the Penicillus. Every time after using it, it should be rinsed in clean water, and wiped dry.

The Penicillus my be procured from Mr. Indwin Hancock, surgical instrument maker, Bath. Thirty-two postage stamps will insure its being sent free to any part of the United Kingdom.

-

\section{ON THE NITROGENOUS WATERS OF BUXTON.}

By C. W. Berr, M.D., K.L.S., Buxton.

Priviodsh to the Reformation the employment of water as a remedial agent was carried to a great extent in England, eopecially in such places as were celebrated for the peculiar virtues or purity of their waters, under the name of saint's or holy wells; but along with the worship of their patron saints, most of them lost much of their supposed miraculous power. It is not a little singular that, though few records of the practice pursued in conducting these cures remain in this country, a most minute account of the processes used by the monks at MIalvern in the treatment of their patients has been preserved in a small quarto rolume,* entitled, Die Englische Wasser-Kur, written in German, and published in Suabia in 1568 . The treatment there described is exactly that which Preissnitz revived in that country about twenty years ago as his own discovery, and which gave rise to what is now considered an entircly new system of water cure.

From time immemorial the waters of Buxton and Bath have been especially celebrated in the cure of gout and rheumatism ; but so different was their chemical composition and temperature, that it appeared strange that their effects should be so much alike. Those of Buxton hare been frequently analysed, and found to contain not more than $20 \frac{1}{2}$ grains of solid material in a gallon, $t$ and of these ingredients not one is of any remarkable efficacy in the cure of disease unless employed in considerable quantity. It was therefore extremely difficult to reconcile the ronderful influence exerted over every form of rheumatism, by a water containing less of mineral ingredients than the purest of ordinary spring waters; but this spring was well known to be charged with some kind of gas, which was seen to escape in large bubbles from the waters, and it is only of late years that this has been recognized as very pure nitrogen gas, the quantity of which, as determined by Dr. Lyon Playfair in the analysis of the water undertaken by him in 1852, at the instance of the Duke of Devonshire, has proved to be much more considerable than had been stated by previous analysts, amounting to no less than 206 cubic inches per gallon, only about $1 \frac{1}{2}$ per cent of the gas evolved being carbonic acid gas.

The waters of Bath contain a much larger proportion of mineral ingredients, consisting of salts of lime and magnesia, common salt, Glauber's salt and silica, to the amount of 142 grains to the gallon, or seven times as much as those of Buxton; but even this impregnation with salts, in themselves tolerably active when taken in large doses, forms so weak a solution, that it would be necessary to evaporate several gallons of Bath water to obtain a dose of salts sufficient to operate as a moderate aperient. From

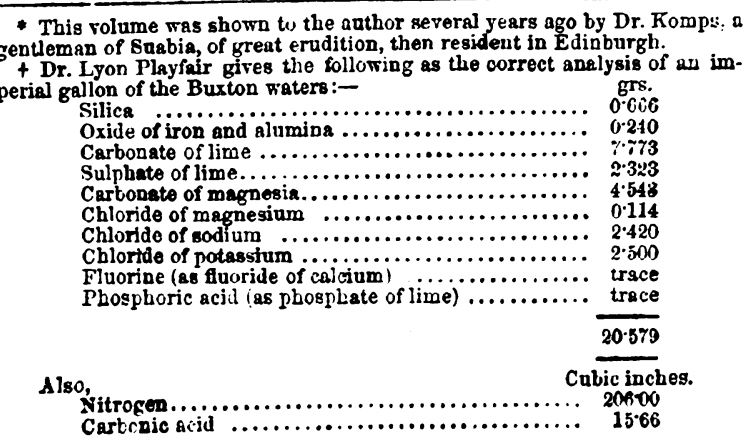

all this it is evident, that whatever virtues tho prings of Bath and Buxton was poseases, the cannot by attributed to the mineral salte which they hold in eolution: they must therafore depend either on thair tenperativen which, as the former issues from the earth at $117^{\circ}$ Falurenheit and the latter at only $82^{\circ}$, is not very likely; or the similar effects they produce on the rheumatic constitution must be due solely to their gaseous contents, for analyin has shewn that from the Bath springs a very considarable quantity of nitrogen gas is evolred, although handly amounting to half the quantity contained in the Burtan waters.

The discovery that to nitrogen gas alonecould beattributed the wonderful effects of these springs has taken the medical world by surprise, and is a fact not yet sufficiently recognised; but we have little doubt more accurate analysis of the continental spas longest celebrated for relieving gout and rheumatism will prove this gas to be the agent an which their efficacy mainly depends, and that as in Bath and Buxton much of what had previously been mistaken for carbonic acid gas is in reality nitrogen.

This gas has always been considered quite inert as a therapeutical agent, having been regarded only as a diluent of the oxygen of the air, which, undiluted, would have proved too exciting to the animal constitution, and therefore we may consider ourselves as living at all times in an air-bath of nitrogen; how then can it be beliered that the same element in which we breathe and have our being can have any special influence upon the constitution when applied to our skins and stomachs through the medium of water, other than it produces when taken in the large quantities we are perpetually inhaling into our lungs? Such considerations, combined with the almost universal opinion entertained by medical men that azote has absolutely no physiological influence on the aniunal frame, may well excuse scepticism as to the Buxton waters possessing any healing properties at all; and we cannot but believe that the publication of the excellent aralysis by Dr. Playfair which we have given above, has greatly contributed to damage the reputation of these so long celebrated baths, by showing that the water is little less pure than distilled water, and contains no active ingrediert whaterer, unless azote be one-an idea which no one, we believe, had up to that time very strenuously advocated, but magra eat veritas et prevalabit. Let any one overfed, little erercised, plethoric, and with some latent tendency to gout make the experiment of remaining ten minutes in the natural bath of Buxton, and he will soon repent of his unbelief. He will experience giddiness and discomfort, pain in the loins, and probably rheumatism in all his limbs, and very likely his temerity will be punished by a plentiful eruption of pimples on the face, effects which he would hardly expect to feel from remaining a few minutes in a tepid bath of pure water, which this would be if nitrogen were really as inert as it is supposed.

In a gouty habit, the effect of incautiously bathing in the Buxton waters without previous preparation is not unfrequently a very sudden and severe attack of gout; but if the system be prepared by an effectual purge and one or two warm baths, the use of the natural waters (as it is customary to term them when of the temperature at which they issue from the spring, $82^{\circ}$ Fahrenheit) is not attended with such severe consequences. In such cases caution is the more requisite in commencing a course of bathing, for while in the bath the gouty or rheumatic patient ing, for whe wonderful mobility and freedom in his stiffened and painful joints, that tempts him to prolong the enjoyment, but after the natural reaction that is due solely to temperature has time to subside he finds his pain: increase, and about two hours after his bath a languor and depression succeeds that might induce him to have recourse to stimulants, an inclination which it would often be injurious to indulge.

Most writers have described the effect of these waters as peculiarly stimulant, but they are in truth in the first instance exactly the reverse. Whan used by a person of seden- 
tas hbit whow interiar is loaded with socmmulation of good living, the immedinte effect is a tendency to congertion of the great rascular organs and renous trunks, disturbing the general circulation, causing confusion of the head, and giving rive to alarming sensations of impending apoplexy ; but the condition of the brain under such circumstances is very similar to that induced by sun-stroike, that is to say, a weakenod and congested rather than an excited state of the circulation of that organ, which will require much judgment in its treatment if the symptoms be serious.

The reaction which immediately follows the use of the bath is due solely to its temperature, and not at all to the presence of azote in the water; but it serves to correct the tendency to congestion, and the depressing effect that would otherwise follow too soon after immersion, from the combined action of cold and the nitrogen of the bath. For this reeson it is better to begin a course of bathing in the Buxton waters with one or two hot baths, in order to ensure the blood being drawn to the skin and so counteracting the congestive tendency, especially in feeble or susceptible constitutions, where there might be a doubt of that reaction taking place which produces the agreeable warm glow over the whole body, such as should follow the use of the cooler baths.

I know not whether this salutary practice was derired from observing that the hotter springs of Bath less frequently produced the more severe symptoms we have mentioned as occasionally met with in the commencement of a course of the natural baths in Buxton; but at all events it is not thought necessary there to restrict the time of remaining in those waters to the extent we are obliged to do here.

The depressing effect, we have before said, is not felt by persons in robust health, but becomes rery sensible in the rheumatic constitution an hour or two after the bath; such in fact are the physiological effects we should a priori expect in a remedial agent of much power in the cure of gout or rheumatism, for all the medicines most employed in the treatment of those diseases, such as colchicum, nitrate of potass, aconite, etc., are peculiarly depressing in their action on the sympathetic system, and to have found the direct effect of the Buxton baths purely stimulant, would have militated against all our preconceived ideas. Btill it is true that in certain cases they appear to be exciting; for reaction succeeds congestion in all diseases that are not immediately fatal, just as fever succeeds the shirering fit in ague: and such is the nature of what is described as "the water fever", commencing after the congestive stage has passed off, from twelve to twenty-four hours after taking the bath. Sometimes this fever is considerable, though this is very rare if due precautions have been observed; and in general the period of reaction, of which "water ferer" is the excess, is not even perceptible to the patient.

From these observations, it will be evident that, however beneficial these waters may prove in cases of rheumatism, gout, dyspepsia, etc., the very qualities that render them so will make them the reverse where any taint of scrofula exists in the constitution; and it is lamentable to see how many cases of hip disease and white swelling of the knee and elbow, strumous ophthalmia, etc., are sent here in hopes of their benefiting by a course of bathing, calculated rather to aggravate their complaints than to cure. It is very desirable on this account that medical men whose patients propose visiting Buxton should be made more fully aware of the nature of the operation of these waters, so different from what, without personal experience of their effects, they would consider likely to result from their chemical composition. It would appear that these are produced solely by a direct influence on the sympathetic system, and through its agency upon the whole of the capillary circulation; for whether used in baths or by drinking, or in both ways at once, these waters produce no constant or palpable effect on any single organ or clace of organ. In some they exhibit laxative proper- ties and in some diuretic, but quite as often they appear to operate in a mannor diametrically opposite, or to have no appreciable action whatever.

Some ingenious attempts hare been made to explain their modus operandi on chemical principles, but our knowledge of organic chemistry modified by vitality has handly yet advanced so far as to enable us to speculate with much safety in that direction. All that can be said with cortaincy as the result of observation, is that, at the first, immersion in the cool tepid bath produces reaction as any other of the same degree of temperature would do, that this reaction is succeeded by languor and a condition somewhat resembling the commercement of the cold fit of ague, which by and by yields to reaction with slight acceleration of the pulse, and these two latter effects we beliere to be due solely to the nitrogen contained in the water.

In so far as we are able to judge, this is the mode in which the Bath and Buxton waters "bring out gout," as it is termed. Bath, especially, is famed in the literature of the last century as being much frequented by those who desired so unpleasant a consummation to their dyspepsias and discomforts as a fit of that malady, and a visit to it was frequently prescribed for that purpose by the celebrated Dr. Mathew Baillie. Immersion for a considerable time in the nitrogenous water is presently succeeded in the gouty or rheumatic constitution, not by the slight depression felt in following out a well regulated course, but by a severe shivering fit, and that by high ferer, rheumatic, or gouty, as it may be. This quality of the waters eliciting the nature of some obsure maladies is most valuable, for though the microscope has done much to aid in the diagnosis of many functional as well as organic disorders, there are forms of dyspepsia and of nervous agitstion and pain so obscure in their nature, that to possess a test, like these waters, capable of exhibiting in how far the rheumatic diathesis may be their source, is invaluable in giving direction to their treatment, or completing their cure. In cases of sciatica or facial neuralgia, this property of unmasking rheumatism is especially valuable, depending, as these painful disorders mainly do on one of four very different causes not always easily distinguished. 1. Bheumatism, which is the most common in this country. 2. Disorder of the digestire organs, frequently mixed up with some rheumatic or gouty tendency. 3. Malaria, which is the principal source of tic and sciatica in India and in ill drained houses in this country. 4. Pressure, irritation, or disease in the course of the nerves which supply the seat of suffering. It will, therefore, be readily believed that every practitioner puzzled with the obscurity which frequently hangs over these piteous cases, would greatly rejoice to have such a certain touchstone and help at hand as we possess in these waters, in the diagnosis and treatment of these often obscure and very painful disorders. In the full faith, then, that by and by, some good reason will be discovered why baths charged with nitrogen should possess power orer the human constitution suffering from a certain class of diseases, such as we could never have guessed at from their chemical contents in the present state of physiological science, we shall be content to believe that the experience of ages has not been wrong in attributing to these springs such virtues, and that the remarkable results from their use we have ourselves witnessed were real, and not creations of our own heated and prejudiced imagination; and that neither were the pains and aches resembling those Prospero promises to Caliban, which we suffered from misuse of the bath in the days of our scepticism, mere fancies; we shall, therefore, now pass on to more general observations. The effects of drinking the waters are not so obvious as those of the baths. Persons in health drink them freely with perfect impunity, and without experiencing any sensation or medicinal action other than would be produced by pure spring water, except that perhaps they may perceive their slight warmth when fresh drawn less unpleasant than pure water uncharged with gas would be at the same temperature; the case, however, 
is rer difierent with persons whose bowels are loaded, or who have any gouty tendency, for in them a glass of this mter will produce very unpleasant sensations of distension in the stomach, and appear to arrest digestion for somo hours, causing feelings like those which frequently usher in a bilious attack. This is especially the case with those whose nervous system has been enfeebled, and their liver affected by spirituous potations.

When a person visiting Buxton with the intention of tating a course of the waters perceives any of the effects above described from drinking a glass or two after breakfast, he will do well to take medical advice before venturing on a course of bathing, otherwise he may chance to leave the place in disgust, much worse than when he arrived, while the very fact of the waters when drank disturbing the functions of the stomach in the first instance ought to have been regarded as the best evidence that the case is of a nature most calculated to profit by their regulated use.

It is notorious that the unpleasant consequences sometimes experienced by persons commencing a self-imposed course of bathing and drinking the waters has often brought Buxton into unmerited disrepute, as aggravating the complaints it is, in reality, most calculated to cure; the sufferers having been frightened away by the manifest increase of their complaints long before any good effects could have been expected to result cren if properly con. ducted. Beneficial effects, such as are calculated to secure the confidence of a patient are seldom experienced in less than a week or ten days, the reverse is more generally the case at first, but the increase of pain which most rheumatic and gouty persons complain of at the commencement of a course is so well known to the habitués, that it is amusing to hear them congratulating new comers on feeling worse, comforting them with the assurance that it is a sure sign the waters will do them good.

There is one singularity in the mode of employing the baths in Buxton, that strikes those who have gone the round of the German baths as very absurd, but its necessity has been fully proved by experience, we allude to the exceedingly short time the patient is permitted to remain in the natural or cool bath at the commencement of a course. $A$ person in perfect health may enjoy such a bath, swimming about and amusing himself in the water as long as he pleases, withoui any sensible effect on his constitution, but we have already said it is far otherwise with the invalid.

When a patient suffering from chronic gout or rheumatism, conversant with the system pursued at most of the continental spas where he had been enjoined to drink the water by pints, and to remain in his bath from half an hour to an hour daily, or even more than once a day, consults a Buxton physicinn, and is told not to take more than half a pint of the waters, and that at twice, and on no account to remain in the natural water more than four minutes to begin with, and not even to use this short immersion every day, he is inclined to consider the whole affair as arrant humbug; but he may find disobedience to these orders, however ridiculous they appear, severely punished. This is more especially illustrated by the sufferings brought upon themselves by those who, having every faith in the efficacy of the remedy, seek to hasten their cure, and to derive the greatest possible amount of good from their stay in Buxton in the least possible time. They hurry to complete the number of baths prescribed, without attending to the caution occasionally to omit their use for a day; some we have known even to take two baths a day, and be laid up so seriously ill in consequence, that they were unable to return to their homes for long after they ought to have been well.

It has appeared the more necessary io address these remarks to the profession, inasmuch as we frequently meet with patients suffering severely in consequence of attempting to pursue a course laid out for them in detail by their "own medical man at home," who, reasoning only on the chemical analysis of the waters, has conceived an erroneous and perhaps rather contemptuous idea of their effects.
It is remarkable how fer of the invalids who frequent Burton, come on the recommendation of their medical advisers, or not rather in spite of their pooh-poohing the notion that good could by any possibility result from their use. This is a pity, as it subjects them to a suspicion of prejudice, or ignorance, or interested motives, very difficult to be overcome in the minds of those who hare derived decided advantage from acting in opposition to their advice and opinion. A large proportion of the annual frequenters of Buxton have been induced to make trial of its efficacy by hereditary tradition, or consists of persons who have discovered for themselves the extraordinary protective powers these waters exert in guarding them from their periodical attacks of gout or rheumatism, a course of twelve baths sufficing to render them safe for the winter. It is thus by no meaus uncommon to hear persons bewail the punishment they have endured from severe attacks, if anything have chanced to interfere with their annual visit to Buxton, and vow that nothing will ever tempt them to forego their batbs for another season. This remarkable persistency in the good effects of these waters is not the least astonishing and incomprehensible of the peculiarities of this singular therapeutic agent.

\section{里eriscope.}

\section{EPIDEMIOLOGY, HYGIENICS, AND STATISTICS.}

SANITARY CONDITION OF THE CITY OF IONDON.

ON Tuesdar, October 14th, Dr. Lethebr, Medical Officer of Health to the City of London, presented to the City Commission of Sewers his first annual report, of which the following is a copious extract :-

GENERAL MORTALITX IN THE CITY.

The total mortality of the year has been 2,910. This number is 490 , or about 14 per cent., less than the average of the last eight years. In fact, the death rate of the whole city has been reduced from a general average of $2 \pm$ per 1,000 of the inhabitants to 22.

The proportions of the death rates of the several districts and sub-districts of the city of London, differ very remarkably, and have contributed very unequally towards the general aggregate; for, while the total mortality of the whole city is at the rate of 24 per 1,000 of the inhabitants, that of the several subdivisions is from 15 to 30 in 1,000 . In the City of London Union, for example, the mortality has been from 15 to 19 in the 1,000 , and in that division of the metropolis which forms the eastern part of the city the number of deaths has been from 22 to 28 in 1,000 , and in one of the most densely crowded of all the metropolitan sub-districts-the southern part of the West London Union, the no tality has risen to 30 in 1,000 . West London Union, the no tality has risen to 30 in 1,000 . Cinion is as low as 17.7 per 1,000 of the inhabitants, but we must not lose sight of the fact that many influences have been at work in keeping down the proportion of deaths which do not strictly belong to the sanitary affairs of the district. One of these arises out of a practice that is universally followed by better classes; namely, that of avoiding as far as possible the aggravating circumstances of a city life, and of moving away into a more bealthy district whenever the hand of sickness is placed upon them. This necessarily causes the exclusion of a large number of deaths which rightly belong to the city rea large num if these circumstances were not duly considered, we should be disposed to imagine that the state of the public health in the very heart of the metropolis is actually better than it is in all England, or even than it is in the average of than rural districts: for according to the last annual report of the Registrar-General, the mortality is at the rate of $22 \cdot 1 \mathrm{p} \in \mathbf{r}$ 1,000 , while that of town districts is $25 \cdot 8$, and that of the coun $20 \cdot 3$. It would, therefore, appear from a superficial country 20.3 . It would, these numbers that the ritality of the city is examination of 24 per cent. better than that of England generally, and 15 per cent. better than that of the rural districts. Such a view of the matter is altogether erroneous.

To judge more accurately of the city mortality, it is necessary 